\title{
EDITORIAL
}

\section{Rational monitoring of COPD: where do current clinical guidelines stand?}

\author{
L. van den Bemt, T. Schermer and C. van Weel
}

$\mathbf{T}$ he Global Initiative for Chronic Obstructive Lung Disease (GOLD) guideline serves as an international reference for evidence-based management of patients with chronic obstructive pulmonary disease (COPD) [1]. Based on the available scientific evidence, recommendations for diagnosis and treatment are presented.

An important goal of the GOLD initiative is to counter the nihilistic attitude and to promote a proactive engagement of physicians and allied healthcare professionals with COPD patients over time [2]. In addition, GOLD, and also other guidelines, recommend regular surveillance of patients' respiratory health status [1, 3-19]. The rationale behind the regular follow-up of patients with chronic conditions, also referred to as "monitoring", is that it facilitates optimal outcome of patient care [20, 21]. However, care of COPD implicates large numbers of patients and, consequently, monitoring their health status would result in substantial use of healthcare resources. In the present paper, the authors reflect on monitoring, as currently recommended in COPD guidelines, and discuss the rationale behind it, including some pros and cons of the procedures involved.

A total of 18 clinical guidelines published or updated after the year 2000 that address the diagnosis, treatment and (end-oflife) care of COPD were analysed (table 1) [1, 3-19]. All but one of these guidelines [19] recommend regular monitoring, in particular of lung function, but also of respiratory symptoms, smoking habits, nutritional status, exercise tolerance and presence or progression of comorbid conditions (table 2) [1, 3-18]. However, none of the guidelines provided evidence for the recommended monitoring. This is not really surprising, as there is a complete lack of empirical studies that have addressed this particular issue. Consequently, recommended monitoring is almost exclusively expert opinion-based and, given the potential impact on costs and resources, this warrants at least some discussion.

In a number of cases the advice to monitor is self-evident, e.g. for smoking cessation, where individually tailored advice and

Radboud University Nijmegen Medical Centre, Dept of General Practice, Nijmegen, The Netherlands. STATEMENT OF INTEREST: None declared.

CORRESPONDENCE: L. van den Bemt, Radboud University Nijmegen Medical Centre, Dept of General Practice (117-HAG), P.0. Box 9101, 6500 HB Nijmegen, The Netherlands. Fax: 31 243541862. E-mail: L.vandenbemt@hag.umcn.nl support require up-to-date information on current smoking status. However, this is not the case for the monitoring of lung function, the most often recommended monitoring routine for patients with COPD. Lung function testing is essential for the diagnosis of COPD and to stage its severity [22], but the progressive decline of lung function is resistant to treatment other than smoking cessation [23]. As a consequence, there is little value in monitoring a patient's lung function decline once the diagnosis has been made. However, as the disease progresses, periodic reassessment of the severity of airflow obstruction enables periodic re-staging and concomitant stage-specific treatment recommendations. An example is treatment with inhaled steroids to prevent exacerbations, which is only recommended for patients with a forced expiratory volume in one second $<50 \%$ of the predicted value $[1,24]$.

Since the majority of patients with COPD suffer from mildto-moderate disease [25] and progression to a more severe disease stage will often take several years, the cost of monitoring lung function in all patients should be offset against its limited yield. Monitoring of nutritional status can be looked at in a similar way: based on current knowledge, monitoring of nutritional status provides information on prognosis in patients with severe-to-very severe COPD [26, 27], but for patients with mild-to-moderate disease the prognostic value of poor nutritional status has not been established. As long as there is no sound evidence that patient outcomes or prognosis can be improved by nutritional intervention, there is no clear purpose for collecting information on nutritional status in patients with mild-to-moderate disease [28, 29].

From this, it can be inferred that monitoring in COPD may serve different goals: grading the severity of the disease [1, 26]; selecting applicable treatment options, i.e. inhaled corticosteroids [24] or oxygen therapy [1]; or predicting the prognosis of the disease. These goals should be reflected in the application of monitoring routines: while assessment of symptoms and initiated treatment may be relevant in every contact with a particular patient, disease severity and prognosis may only require occasional reassessment. This adds relevance to the basic concept of GOLD, which has made disease staging the starting point of treatment recommendations [1]. Compared with patients with more severe COPD, it seems that the majority of patients with mild-to-moderate disease do not yet exhibit reduced exercise tolerance, loss of 
TABLE 1 Clinical practice guidelines for chronic obstructive pulmonary disease

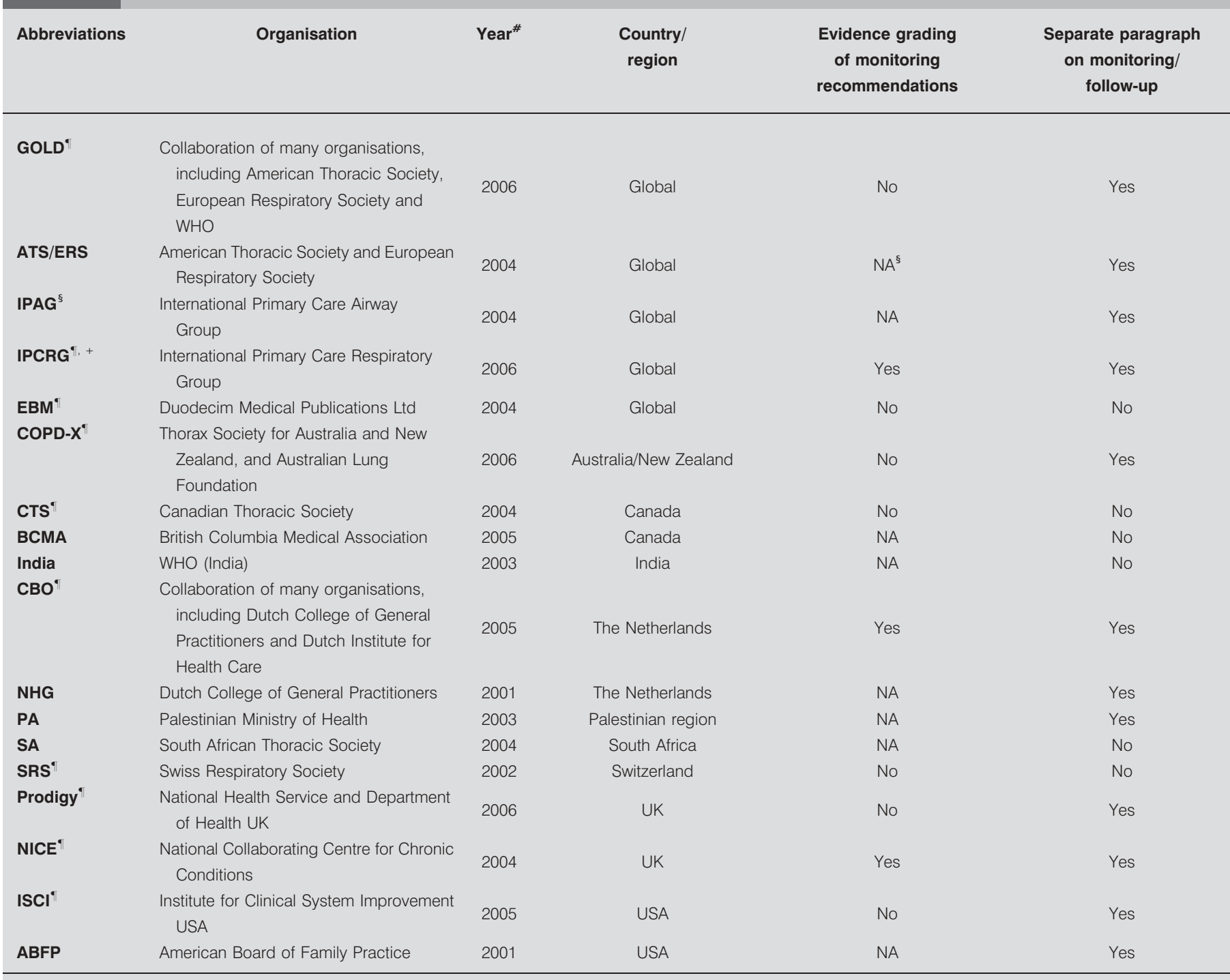

GOLD: Global Initiative for Chronic Obstructive Lung Disease; WHO: World Health Organization; EBM: Evidence-Based Medicine Guidelines; CBO: Dutch Institute for Healthcare Improvement; NA: not applicable. *: year of initial publication or, in the case of periodic revision of the guideline, the year of the most recent update; ": evidence grading for at least one recommendation in the guideline; ${ }^{+}$: guidelines developed by the same group of experts; ${ }^{\text {s }}$. not applicable since the guideline did not use systematic evidence grading.

body mass [30] or frequent exacerbations [31]. For this reason, it would make sense to recommend some monitoring procedures, especially the monitoring of symptoms and smoking status, as routine for every patient with COPD, and apply additional surveillance on the basis of disease severity stage. This would not only help to tailor care to the individual patients, but also prevent a lot of effort and resources being used for the routine collection of information that has no direct relevance to the management of the patient. A baseline severity staging at the time of diagnosis followed by reassessment once every few years in patients with mildto-moderate disease may well be sufficient. Based on the disease stage and other patient-related factors (e.g. the presence of comorbid conditions), monitoring of exercise tolerance, loss of fat-free body mass or frequent exacerbations could be adjusted.

This will preserve time, equipment and facilities for those individuals in greatest need, an aspect that is particularly relevant given the fact that the number of patients with chronic obstructive pulmonary disease will continue to increase in years to come [32]. At the same time, researchers should take up the challenge to establish further evidence of the benefits and cost of monitoring patients with chronic obstructive pulmonary disease in well-designed studies. After all, if monitoring chronic obstructive pulmonary disease is crucial for facilitating optimal patient care, do evidence-based chronic obstructive pulmonary disease guidelines not deserve an evidence-based paragraph on monitoring? 


\begin{tabular}{ll}
\hline TABLE 2 & $\begin{array}{l}\text { The most frequently recommended monitoring } \\
\text { routines in clinical practice guidelines for chronic } \\
\text { obstructive pulmonary disease }\end{array}$ \\
\hline Monitoring routines & $\begin{array}{c}\text { Guidelines } \\
\text { mentioning monitoring } \\
\text { routine }\end{array}$ \\
\hline Total & 18 \\
Lung function & $15(83)$ \\
Symptoms/dyspnoea & $14(78)$ \\
Smoking habits & $12(67)$ \\
Exercise tolerance & $10(56)$ \\
Comorbidity/complications & $10(56)$ \\
Exacerbations & $9(50)$ \\
Inhaler technique & $8(44)$ \\
Side-effects of treatment & $8(44)$ \\
Effect of drug treatment & $7(39)$ \\
Nutritional condition & $7(39)$ \\
Compliance with treatment & $7(39)$ \\
\hline
\end{tabular}

Data are presented as $\mathrm{n}$ or $\mathrm{n}(\%)$. Only routines that are recommended in seven or more of the guidelines are shown.

\section{REFERENCES}

1 Global Initiative for Chronic Obstructive Lung Disease (GOLD). www.goldcopd.com. Date last accessed: November, 2006.

2 van der Palen J, Monninkhof E, van der Valk P, Visser A. Managing COPD: no more nihilism! Patient Educ Couns 2004; 52: 221-223.

3 National Collaborating Centre for Chronic Conditions, Chronic obstructive pulmonary disease. National clinical guideline on management of chronic obstructive pulmonary disease in adults in primary and secondary care. Thorax 2004; 59: Suppl. 1, 1-232.

4 American Thoracic Society, European Respiratory Society. Standards for the diagnosis and management of patients with COPD. http://dev.ersnet.org/275-guidelines.htm. Date last accessed: October, 2006.

5 Geijer RMM, van Schayck CP, van Weel C, et al. NHGStandaard COPD: behandeling. [Dutch College of General Practitioners guideline treatment of COPD.] Huisarts Wet 2001; 44: 207-219.

6 Richtlijn Ketenzorg COPD. www.cbo.nl/product/richtlijnen/folder20021023121843/copd_2005.pdf/view. Date last accessed: October, 2006.

7 The Australian Lung Foundation, The Thoracic Society of Australia and New Zealand. Chronic obstructive pulmonary disease (COPD) Australian and New Zealand management guidelines and the COPD handbook (COPD-X). www. copdx.org.au/guidelines/index.asp. Date last accessed: October, 2006.

8 Institute for Clinical System Improvement (ICSI). Chronic obstructive pulmonary disease (guideline). www.icsi.org/ guidelines_and_more/guidelines_order_sets__protocols / respiratory/chronic_obstructive_pulmonary_disease/chronic_ obstructive_pulmonary_disease_guideline_.html. Date last accessed: October, 2006.
9 International Primary Care Airways Group. IPAG diagnosis and management handbook. Chronic airways diseases: a guide for primary care physicians. www. globalfamilydoctor.com/pdfs/IPAGHandbook.pdf. Date created: January, 2005. Date last accessed: October, 2006.

10 Bellamy D, Bouchard J, Henrichsen S, et al. International Primary Care Respiratory Group (IPCRG) Guidelines: management of chronic obstructive pulmonary disease (COPD). Prim Care Respir J 2006; 15: 48-57.

11 Shahin S, Attar H, Eshtawy J, et al. Palestinian guideline for diagnosis and management of chronic obstructive pulmonary disease. Quality improvement program, Ministry of Health, Palestine, 2003.

12 Canadian Thoracic Society. Executive Summary Canadian Thoracic Society. Recommendations for management of chronic obstructive pulmonary disease-2003. www.pulsus. com/Respir/10_SA/contents.htm. Date last accessed: October, 2006.

13 O'Donnell D-E, Aaron S, Bourbeau J, et al. Canadian Thoracic Society recommendations for management of chronic obstructive pulmonary disease-2003. Can Respir J 2003; 10: Suppl. A, 11A-65A.

14 National Health Service (NHS). Prodigy guidance: chronic obstructive pulmonary disease. www.prodigy.nhs.uk/ chronic_obstructive_pulmonary_disease. Date last accessed: October, 2006.

15 British Columbia Medical Association (BCMA). GPAC: Guidelines and Protocols Advisory Committee. Chronic obstructive pulmonary disease (COPD). www.health. gov.bc.ca/gpac/guideline_copd.html. Date last accessed: October, 2006.

16 Jindal SK, Gupta D, Aggarwal AN. Guidelines for management of chronic obstructive pulmonary disease (COPD) in India: a guide for physicians (2003). Indian J Chest Dis Allied Sci 2004; 46: 137-153.

17 Russi EW, Leuenberger P, Brandli O, et al. Management of chronic obstructive pulmonary disease: the Swiss guidelines. Official Guidelines of the Swiss Respiratory Society. Swiss Med Wkly 2002; 132: 67-78.

18 Bateman ED, Feldman C, O'Brien J, Plit M, Joubert JR; COPD Guideline Working Group of the South African Thoracic Society. Guideline for the management of chronic obstructive pulmonary disease (COPD): 2004 revision. S Afr Med J 2004; 94: 559-575.

19 Kinnula V. Evidence-based medicine guidelines: chronic obstructive pulmonary disease. www.ebm-guidelines.com. Date last accessed: July, 2006.

20 Glasziou P, Irwig L, Mant D. Monitoring in chronic disease: a rational approach. BMJ 2005; 330: 644-648.

21 Grol R, Cluzeau FA, Burgers JS. Clinical practice guidelines: towards better quality guidelines and increased international collaboration. Br J Cancer 2003; 89: Suppl. 1, S4-S8.

22 Anthonisen NR, Wright EC, Hodgkin JE, the IPPB Trial Group. Prognosis in chronic obstructive pulmonary disease. Am Rev Respir Dis 1986; 133: 14-20.

23 Anthonisen NR, Skeans MA, Wise RA, Manfreda J, Kanner RE, Connett JE. The effects of a smoking cessation intervention on 14.5-year mortality: a randomized clinical trial. Ann Intern Med 2005; 142: 233-239.

24 Jones PW, Willits LR, Burge PS, Calverley PMA. Disease severity and the effect of fluticasone propionate on chronic 
obstructive pulmonary disease exacerbations. Eur Respir J 2003; 21: 68-73.

25 Hoogendoorn M, Feenstra TL, Schermer TR, Hesselink AE, Rutten-van Molken MP. Severity distribution of chronic obstructive pulmonary disease (COPD) in Dutch general practice. Respir Med 2006; 100: 83-86.

26 Celli BR, Cote CG, Marin JM, et al. The body-mass index, airflow obstruction, dyspnea, and exercise capacity index in chronic obstructive pulmonary disease. $N$ Engl J Med 2004; 350: 1005-1012.

27 Schols AM, Broekhuizen R, Weling-Scheepers CA, Wouters EF. Body composition and mortality in chronic obstructive pulmonary disease. Am J Clin Nutr 2005; 82: 53-59.

28 Ferreira IM, Brooks D, Lacasse Y, Goldstein RS, White J. Nutritional supplementation for stable chronic obstructive pulmonary disease. Cochrane Database Syst Rev 2002; 1: CD000998.
29 Creutzberg EC, Wouters EF, Mostert R, WelingScheepers CA, Schols AM. Efficacy of nutritional supplementation therapy in depleted patients with chronic obstructive pulmonary disease. Nutrition 2003; 19: 120-127.

30 Steuten LM, Creutzberg EC, Vrijhoef HJ, Wouters EF. COPD as a multicomponent disease: inventory of dyspnoea, underweight, obesity and fat free mass depletion in primary care. Prim Care Respir J 2006; 15: 84-91.

31 Schermer TR, Saris CG, van den Bosch WJ, et al. Exacerbations and associated healthcare cost in patients with COPD in general practice. Monaldi Arch Chest Dis 2006; 65: 133-140.

32 Murray CJ, Lopez AD. Alternative projections of mortality and disability by cause 1990-2020: Global Burden of Disease Study. Lancet 1997; 349: 1498-1504. 